Article (refereed)

Rowland, C. S.; Balzter, H.; Dawson, T. P.; Luckman, A.;

Patenaude, G.; Skinner, L.. 2008 Airborne SAR monitoring of tree growth in a coniferous plantation. International Journal of Remote Sensing, 29 (13). 3873 - 3889. doi:10.1080/01431160801891796

(C) 2008 Taylor \& Francis

This version available at http://nora.nerc.ac.uk/4434/

NERC has developed NORA to enable users to access research outputs wholly or partially funded by NERC. Copyright and other rights for material on this site are retained by the authors and/or other rights owners. Users should read the terms and conditions of use of this material at http://nora.nerc.ac.uk/policies.html\#access

This is an electronic version of an article published in International Journal of Remote Sensing, 29 (13)pp 3873-3889. The International Journal of Remote Sensing is available online at informaworld ${ }^{\mathrm{TM}}$ http://www.informaworld.com/10.1080/01431160801891796 


\title{
Airborne SAR monitoring of tree growth in a coniferous plantation
}

\author{
Authors:
}

C.S. Rowland** ${ }^{1}$, H. Balzter ${ }^{2}$, T.P. Dawson ${ }^{3}$, A. Luckman ${ }^{4}$, G. Patenaude ${ }^{5}$ and L.

Skinner ${ }^{4}$

${ }^{*}$ Corresponding author. Email: $\underline{\text { clro@,ceh.ac.uk }}$

${ }^{1}$ Centre for Ecology and Hydrology Monks Wood, Section for Earth Observation, Abbots Ripton, Huntingdon, Cambridgeshire, PE28 2LS, UK

${ }^{2}$ University of Leicester, Department of Geography, Bennett Building, University Road, Leicester, LE1 7RH, UK

${ }^{3}$ CECS, University of Edinburgh, John Muir Building, Mayfield Road, Edinburgh, UK

${ }^{4}$ Department of Geography, University of Wales, Swansea, UK

${ }^{5}$ School of GeoSciences, University of Edinburgh, Drummond Street, Edinburgh, Scotland, UK 


\begin{abstract}
This paper examines three empirically based methods of monitoring forest growth between 1991 and 2000 from airborne synthetic aperture radar (SAR). In the first method, height change and volume change between 1991 and 2000 were estimated from the mean L-band stand backscatter difference between the two dates. Height change and volume change over the nine year period were estimated with an accuracy of $0.23 \mathrm{~m}$ and $15 \mathrm{~m}^{3} /$ ha respectively, when the stands were below saturation point for the first date. The accuracy of the results was lower for stands beyond saturation in both data sets. In the second method, height change is calculated from estimated stand height in 2000 minus estimated stand height in 1991. The second method produced poorer results than the first method, but better results than predicted by the error propagation equation. The difference between the observed accuracy and the expected error (based on the error propagation equation) appears to be due to a systematic bias in both the 1991 and 2000 estimates, as the residuals are correlated for stands below 20 years old $(\mathrm{r}=0.71$ for stand volume residuals). The third experiment investigates the utility of data from two dates to classify the stands into three age classes. The results show that, with two images separated by nine years, $85 \%$ of stands were correctly classified compared to $69 \%$ for a single date L-HV image.
\end{abstract}

Keywords: AirSAR; E-SAR; Thetford forest; change detection; forest; timber volume; canopy height 


\section{Introduction}

Terrestrial biotic carbon stores are a key element to understanding climate change, although they are difficult to assess and current estimates have high uncertainties attached (Gupta et al., 2003). Radar remote sensing is one of a range of remote sensing technologies, which potentially has a role to play in reducing the uncertainty in monitoring and mapping forest change and growth. Radar remote sensing studies have tended to focus on single date imagery and investigating the sensitivity of radar backscatter to biomass and related biophysical variables (Dobson et al., 1992; Le Toan et al., 1992; Ranson \& Sun, 1994; Harrell et al., 1995; Harrell et al., 1997). The uptake of multi-temporal SAR remote sensing for forest change has been limited by the availability of suitable archives of SAR imagery and the biomass-dependent saturation of the SAR signal, which becomes especially limiting if only one band (a single polarisation at a single wavelength) is available.

Saturation point is the point at which increases in forest biomass, height or volume no longer cause a detectable change in observed backscatter. The backscatter response from forest is highly wavelength and polarization dependent. Shorter wavelength X-band ( 3 $\mathrm{cm})$ and C-band $(\sim 5 \mathrm{~cm})$ signals are scattered from the smaller sized components of the forest canopy, usually from leaves and twigs, so have limited interaction with the tree trunk. Given that the tree trunk generally accounts for $75 \%$ of the aboveground biomass for Corsican pine (Pinus nigra) and Scots pine (Pinus sylvestris) in the UK (Levy et al., 2004) shorter wavelengths are of limited use in estimating aboveground biomass (Imhoff, 1995a). Longer wavelengths such as L-band $(\sim 23 \mathrm{~cm})$ and P-band $(\sim 68 \mathrm{~cm})$ penetrate further through the canopy and typically interact with branches or tree trunks providing a better source for estimating forest biomass. One consequence of wavelength dependent scattering 
interactions is that saturation is wavelength dependent. The C-band typically saturates at around 20t/ha, the L-band at around 40 to $100 \mathrm{t} / \mathrm{ha}$ and P-band at around 100 to 200t/ha (Dobson et al., 1992; Imhoff, 1995b). However, the saturation point is very dependent upon forest structure and for deciduous canopies biomass values of $40 \mathrm{~kg} / \mathrm{m}^{2}$ (equivalent to 400t/ha) without reaching saturation point have been reported (Ferrazzoli et al., 1997). An alternative method of extending the saturation point to higher biomass levels is via Very High Frequency (VHF) airborne data sets which have shown no signs of saturating at biomass levels of 375t/ha for Norway spruce and Scots pine forest (Fransson et al., 2000). Different polarisations vary in their sensitivity to biomass, with cross-polarised signals tending to be most sensitive (Kasischke et al., 1997).

A number of approaches have been proposed which extend the range for which accurate estimates can be made beyond the saturation point. The methods all use more input data than just a single wavelength and polarisation. For example, multi-frequency data can be used through multivariate relationships or multi-frequency ratios (e.g. Ranson \& Sun, 1994; Ranson et al., 1995; Harrell et al,. 1997), alternatively additional information such as forest structural type classifications (Dobson et al., 1995; Kasischke et al., 1995; Harrel et al., 1997) can be incorporated, typically in multi-stage approach.

Multi-temporal radar work has tended to focus mainly on using multi-date imagery to characterise more accurately forest state for a limited period of time, either via classification based studies using temporal backscatter profiles to discriminate between cover types (Conway, 1997; Van de Griend \& Seyhan, 1999; Miles et al., 2003), to optimise estimates of backscatter (Quegan et al., 2000) or to determine the optimum time of year, or weather conditions, for estimating biophysical variables from backscatter (Wang et 
al., 1994; Harrell et al., 1995; Ranson et al., 1995; Harrell et al., 1997; Fransson \& Israelsson, 1999; Kurvonen et al., 1999; Pullianien et al., 2003) or coherence (Fransson et al., 2001). Multi-temporal backscatter has been used to investigate boreal forest disturbances, including logging, insect damage and fire damage (Ranson et al., 2003). Logging activities have also been successfully detected using multi-temporal coherence (Smith \& Askne, 2001). L-HH backscatter change has been used to estimate forest growth between 1978 and 1997 using SEASAT and JERS-1 L-HH backscatter (Balzter et al., 2003).

The potential for multi-temporal L-band remote sensing of forests will increase as ALOS-PALSAR, SAOCOM-1 and TerraSAR-L become operational and complement existing JERS-1 and SIRC data archives. Timing of data acquisition is important, because if the period between the two data acquisitions is too short, then too little growth will have occurred to be detectable above measurement error. Conversely, if the period is too long then stands will reach saturation level, which we expect to limit the utility of multitemporal monitoring. This paper presents an investigation of the utility of airborne multitemporal SAR for monitoring forest growth, specifically stand height and volume change. The results of three methods of monitoring forest change over a 9 year period are reported.

\section{Data and Methods}

\subsection{Field site}

The study area is Thetford Forest, which lies over the Suffolk-Norfolk border in East Anglia, UK and is a relatively flat lowland forest. Thetford Forest is a Forestry 
Commission (FC) owned site and is managed primarily for timber production, as a consequence stands are mono-species and mono-age. Most of the stands are Corsican or Scots pine planted during the last 80 years. The analysis in this paper is limited to Corsican pine, as the Scots pine age distribution is uneven (very young or old stands, with few stands between the two extremes).

At Thetford, Corsican pine tree numbers vary from 2000-3000 trees/ha for young, unthinned stands down to 200 trees/ha for mature stands. This corresponds to a maximum timber volume of around $650 \mathrm{~m}^{3} / \mathrm{ha}$ and a maximum height of $32 \mathrm{~m}$. Between 1991 and 2000 , the period of interest, the range of tree height change (growth) was from $1.5 \mathrm{~m}$ for mature stands to $5.7 \mathrm{~m}$ for young stands, with volume changing by $40 \mathrm{~m}^{3} / \mathrm{ha}$ for young stands to a maximum of $130 \mathrm{~m}^{3} /$ ha for stands $20-40$ years old (equivalent to the middle stage of the plantation stand's lifecycle).

\subsection{Forestry data}

The species, age and yield class of each stand are known and specified in a GIS database developed and maintained by the FC. Yield class is essentially a measure of expected vegetation growth rate that allows timber yield models to be tailored to fit the environmental conditions of specific stands. The Corsican pine stands at Thetford are in yield classes 12, 14, 16 and 18, although the majority are class 14 . From the information provided by the FC GIS it is possible to use forest yield models (Edwards \& Christie, 1981) to determine the expected timber volume and stand top height at a given age, based on knowledge of the species and yield class. Timber volume is defined as the trunk volume, 
excluding bark and also branches, and for the Corsican pine stands at Thetford is strongly correlated with tree height $\left(\mathrm{r}^{2}=0.99\right.$ when fitted with a second order polynomial).

The FC yield models provide model estimates from 5 years prior to the first thinning event and onwards. The time of this first thinning varies slightly depending on yield class and species, but the FC yield curves relevant to this study start at between 15-20 years, so it was necessary to extrapolate the yield curves to get estimates of tree height and volume for stands below this point. Field measurements made in June 2000 at 24 stands (Skinner, 2002) enable us to test how accurately the fit is between the measured data and; i) the extrapolated sections of the yield curves, ii) the interpolated sections of the yield curves, and iii) all 24 stands (interpolated and extrapolated stands combined) (table 1).

The RMSE between the field measured height data and the extrapolated yield curve stands is $0.99 \mathrm{~m}$ (based on 14 stands covering a height range of $1.8-9.5 \mathrm{~m}$ ), compared to $1.06 \mathrm{~m}$ for the interpolated stands (based on 10 stands with a height range of 10.0-30.0m) (table 1). This produces a stand height RMSE for all 24 stands of $1.02 \mathrm{~m}$ (table 1). Field timber volume estimates for Thetford, using FC stocking levels (Edwards \& Christie, 1981) and field measurements of diameter at breast height (DBH) and tree height, were also compared to the estimates predicted by the FC yield models. The RMSE for all 24 stands was $34.63 \mathrm{~m}^{3} / \mathrm{ha}\left(\mathrm{r}^{2}=0.95\right)$ for stand timber volumes from $6-600 \mathrm{~m}^{3} / \mathrm{ha}$. The RMSE between the field data estimates and the extrapolated values of timber volume is $26.28 \mathrm{~m}^{3} / \mathrm{ha}$ and $45.25 \mathrm{~m}^{3} /$ ha for the interpolated FC yield model stands and the field measurement-derived estimates.

The RMSE values in table 1 are higher for the extrapolated stands than for the interpolated stands, because the height and volume values are higher for the interpolated 
stands. Overall, the similarity between the FC data and the ground data is high suggesting that the FC GIS data and yield models (both extrapolated and interpolated) can be used as a proxy for ground data.

\subsection{Airborne SAR data}

Airborne repeat-pass L-band fully polarimetric Interferometric Synthetic Aperture Radar (InSAR) data, in wide-swath mode, were acquired over Thetford forest on $31^{\text {st }}$ May 2000 by the E-SAR sensor. The E-SAR data were collected as part of the SAR and Hyperspectral Airborne Campaign (SHAC) and revisited the area imaged by AirSAR in July 1991 during the Maestro campaign (table 2) (Baker \& Mitchell, 1992). The two data sets covered a common area of $8 \mathrm{~km} \times 5 \mathrm{~km}$ and the E-SAR flight-line ran parallel to the AirSAR flightline providing similar incidence angles for the AirSAR and E-SAR images to enable comparison. The AirSAR and E-SAR data were geocoded and the backscatter coefficient, $\sigma^{0}(\mathrm{~dB})$, was calculated.

The E-SAR sensor is operated by the German Aerospace Centre (DLR) and was flown on a Dornier D0228 aircraft. The NASA/JPL airborne SAR (AirSAR) is, like ESAR, a fully polarimetric sensor. Both sensors have L-band SAR operating at $1.25 \mathrm{GHz}$ (Horn 1996; Lou et al., 1996). AirSAR flies at a nominal altitude of 8000m and a speed of 420 knots (Lou et al., 1996), so is less affected by turbulence than the E-SAR sensor which flew the Thetford site at just over $3000 \mathrm{~m}$ and a velocity of $88 \mathrm{~m} / \mathrm{s}$ (171 knots). To counter the turbulence encountered at E-SAR's relatively low altitude and airspeed accurate motion compensation is required (Horn, 1996). E-SAR data is absolutely calibrated and regular 
calibration flights are conducted (Horn, 1996). AirSAR's calibration is maintained by collecting test data on each flight day and by collecting calibration data at the start of each data take (van Zyl, 1992). E-SAR's absolute radiometric calibration is typically $\leq 3 \mathrm{~dB}$ and $\leq 1 \mathrm{~dB}$ relative calibration (DLR, 2007). AirSAR's absolute calibration is also generally $\leq$ $3 \mathrm{~dB}$, whilst relative accuracy is $\leq 1.5 \mathrm{~dB}$ between the 3 wavelengths and $\leq 0.5 \mathrm{~dB}$ between polarisations (Lou et al., 1996). Phase calibration between HH and VV polarisations is $\leq$ $10^{\circ}$ for both sensors (Lou et al., 1996; Horn, 1996).

Comparison of the E-SAR data with corner reflectors at the site gives approximate calibration accuracies of $1.70 \mathrm{~dB}$ for L-HH and $0.87 \mathrm{~dB}$ for L-VV (Saich et al., 2003). Calibration of the 1991 AirSAR data, with corner reflectors, suggested the L-band data were accurate to within $1 \mathrm{~dB}$ (Luckman \& Baker, 1994). The key difference between the AirSAR and E-SAR data sets is the flight altitude that results in higher spatial resolution and increased turbulence for the E-SAR sensor in comparison to the AirSAR sensor.

Preliminary analysis of the relationships between E-SAR $\sigma^{0}$ and timber volume and height revealed a wide backscatter variance beyond saturation point, primarily due to the influence of incidence angle. The AirSAR data were also found to show a slight incidence angle effect of $0.045 \mathrm{~dB} /$ degree, compared to the E-SAR effect of $0.18 \mathrm{~dB} /$ degree (values cited are for L-HV). Consequently, a sensor-specific, polarisation-specific correction for incidence angle (Baker et al., 1994) was applied to the stands beyond saturation point. The correction was only applied to the stands beyond saturation point, because most of the stands at Thetford are beyond saturation point, so we could be confident of deriving a good empirical correction, whereas the number of stands below saturation point is more limited and they are unevenly distributed across the image. 
An edge-eroded version of the FC polygons was used to create a mask to identify the pixels to use when extracting mean stand values. Stands below 1 ha after polygon erosion were excluded from analysis.

Given the general relationship between L-band radar backscatter, for a single polarisation (e.g. L-HH or L-HV or L-VV), and stand height or volume we expect to identify three main types of behaviour between the backscatter values in 1991 and 2000:

- New growth - strong backscatter decrease (i.e. AirSAR backscatter higher than E-SAR) due to the stand being clearcut and replanted between 1991 and 2000, so the trees are 0 to 9 years old in 2000 .

- Young growth - strong backscatter increase (i.e. E-SAR backscatter higher than AirSAR backscatter) due to the increase in biomass (stem and foliage) equivalent to the 10-20 year stage of tree growth before the stand reaches densities where it causes the radar signal to saturate.

- Mature stands - no change (or very low change) in backscatter as the stands have reached L-band saturation point. For the Thetford L-band data this corresponds approximately to trees 20 years or older.

Table 3 shows the number of stands falling into each of these categories and the equivalent height and volume ranges.

\subsection{Neural network method}

Artificial neural networks were used in the backscatter differencing and the height / volume differencing methods, to develop non-parametric, empirical relationships between 
backscatter and the respective biophysical variable. Neural networks are subject to overtraining, especially with limited data sets, and are effectively a 'black-box' model, providing no understanding of the underlying physical or biophysical mechanisms. The advantage in this case is that a preliminary study showed neural networks produced higher accuracy than standard multivariate statistical methods (Rowland et al., 2003) and neural networks can incorporate a range of input data sources, without needing a pre-defined form of multivariate relationship.

The neural networks used in the experiments described in 2.5.1 and 2.5.2 were 1hidden layer back-propagation networks trained with a Levenberg-Marquardt based learning algorithm. Half the data (117 stands) were used to train the neural network, with the other half used as an unseen test data set to assess the accuracy of the neural network. The data were randomly divided to create the testing and training sets. 100 neural networks were trained, for each suite of input and output parameters, with the best network (lowest RMSE) being chosen to produce the results. All $\mathrm{r}^{2}$ and RMSE values cited are for FC predicted values compared to neural network estimated values, where the networks are applied to the unseen test data set, not the training data set.

\subsection{Experiments}

Our aim was to estimate forest change over a 9 year period from airborne SAR data. Two experiments for quantifying forest growth (height and volume change), using neural network derived empirical relationships, and one experiment into classifying forest age, were conducted: 
1) Backscatter differencing - estimation of growth from L-band backscatter difference between 1991 and 2000, using L-band, as it is the only wavelength common to the AirSAR and E-SAR data acquisitions for Thetford.

2) Height / Volume differencing - estimation of growth from the difference between ESAR and AirSAR derived estimates of height and volume for 1991 and 2000.

3) Image thresholding - thresholding three images into age classes. Two of the images quantify change between 1991 and 2000, whilst the third is a single-date image (ESAR L-HV image). The single-date image was thresholded to determine whether the dual-date capability improved accuracy beyond that achievable with a singledate acquisition only.

Stands that were clear-cut and replanted between 1991 and 2000 were only included in the difference image method (experiment 3).

2.5.1 Backscatter differencing to estimate forest growth. The difference in mean stand L-HH, L-HV and L-VV backscatter, between the 1991 AirSAR data and 2000 E-SAR data, was used to train a number of neural networks to estimate change in stand height and volume for the young and mature age classes. The network structure was three L-band difference values as input (L-HH, L-HV and L-VV), one hidden layer and one output value (height or volume change estimate). The results were validated against the expected height and volume change derived from the FC database in conjunction with the yield models. 
2.5.2 Height / Volume differencing to estimate forest growth. This method involved generating height and volume estimates from both the 1991 AirSAR and 2000 E-SAR data and then calculating the difference between the 1991 and 2000 estimates. Previous work had identified the most accurate neural network solutions, for the estimation of height and volume in 1991 and 2000 from the AirSAR and E-SAR data (Rowland et al., 2003). The most accurate AirSAR neural network identified used nine inputs, specifically standwise estimates of $\mathrm{HH}, \mathrm{VH}, \mathrm{VV} \sigma^{0}$ for the C-, L- and P-bands and produced either estimates of stand height or stand volume. The E-SAR neural networks had standwise estimates of LHH, L-HV and L-VV backscatter, plus the interferometric coherence for the L-HH, L-HV and L-VV polarisations and again estimated either stand height or stand volume for the young and mature classes. The stands making up the testing and training data sets were kept consistent for both the AirSAR and E-SAR data, allowing changes in height to be calculated for a consistent set of test stands. The difference between the 1991 and 2000 height estimates was then calculated and compared to the FC based estimates. Note the volume of input data is higher in this experiment than for the preceding experiment, this will be discussed in the results (section 3.2).

2.5.3 E-SAR minus AirSAR difference image. Two difference images were created by resampling the E-SAR L-HV image to the same spatial resolution as the AirSAR L-HV image (table 2), then calculating the stand mean backscatter followed by:

$$
\begin{aligned}
& \sigma_{\text {ratio }}^{0}=E-S A R \sigma^{0}-\text { AirSAR } \sigma^{0} \\
& \sigma_{\text {diff }}^{0}=\log 10\left(\left|E-S A R \sigma^{0}{ }_{\text {lin }}-\operatorname{AirSAR} \sigma^{0}{ }_{\text {lin } \mid}\right|\right)
\end{aligned}
$$


Where $\sigma^{0}$ ratio is the ratio of E-SAR to AirSAR $\sigma^{0}$ as the subtraction of two logarithmic numbers gives the ratio. $\sigma_{\text {diff }}^{0}$ is the difference between AirSAR and E-SAR calculated from the linearly transformed backscatter, $\sigma^{0}$ lin. For comparison a third classification of stand age was produced using mean stand E-SAR L-HV backscatter, to assess whether the combination of E-SAR and AirSAR data provided a better result, than a single image could provide. The two difference images and the E-SAR L-HV image were thresholded to identify three age classes of trees (new stands, young stands and mature stands). The thresholds for the three images were determined from frequency distributions of backscatter or backscatter difference for the three classes (figure 1). Basing the thresholds on the frequency distributions for the three age classes was possible in this case, although we recognise it is only possible in cases where extensive ground data are available. The thresholds were derived from the frequency distributions to identify the optimum class separation and hence maximize the accuracy achieved. Only the HV polarisation data were used for this experiment as the cross-polarised backscatter is most sensitive to variations in biomass (Le Toan et al., 1992; Ranson \& Sun, 1994; Harrell et al., 1995; Harrell et al., 1997; Lucas et al., 2006).

\section{Results}

\subsection{Backscatter difference to estimate forest growth}

To assess how the accuracy of the results is affected by stand age the results in table 4 are reported for five age categories. The five age categories are: 1) Stands that were mature in 1991; 2) stands that were mature in 2000; 3) stands falling into the young class in 1991; 4) 
stands classed as young in 2000; 5) combined 'young and mature' class combining all the stands used in experiments 1 and 2 (see table 3 for young and mature stand definitions).

Figure 2(a) shows that the height change for stands below saturation point in 1991 (the 'young in 1991' class RMSE $=0.23 \mathrm{~m}$ ) is more accurately estimated than for stands above saturation point in 1991 (the 'mature in 1991' class RMSE $=0.64 \mathrm{~m})$ (table 4). The same pattern is shown for the split between young and mature stands in 2000. In the case of volume change, the residuals display high scatter at all levels of change, so the distinction between young and mature stands is unclear (figure 2(b)). Despite this the volume change RMSE is lower for the young classes, than for the mature classes, although the difference is less than for the height change results.

The height change results show that for stands below saturation (i.e. classified as young) in either 1991 or 2000 the height change can be estimated with a RMSE of about $0.2 \mathrm{~m}$. However, no additional accuracy is gained if the stand is young on both dates (compare the 'young in 1991' RMSE of $0.23 \mathrm{~m}$ to the 'young in 2000' RMSE of $0.20 \mathrm{~m}$ ), whereas if the stand is mature in 1991 and 2000 , then the accuracy drops to $0.6 \mathrm{~m}$, as the backscatter change contains no information on forest height change. Similar results are observed for volume change.

These results suggest that empirically relating backscatter change to height change is a useful technique for assessing growth rates of younger forest stands, although the method is less successful for stand volume. 


\subsection{Height / Volume differencing to estimate forest growth}

The best estimates of tree height for 1991 and 2000, for the 'young and mature class', produce errors of $1.75 \mathrm{~m}$ (figure $3(\mathrm{a})$ ) and $2.50 \mathrm{~m}$ (figure $3(\mathrm{~b})$ ) respectively (table 5). Due to saturation this error is non-linear, with higher errors typically incurred as tree height increases. The height difference between the 2000 and 1991 estimates of height produced an RMSE of 2.93m, which is too high for any practical application (figure 3(c)). Likewise the timber volume change for the 'young and mature' class at RMSE $=70.29 \mathrm{~m}^{3} / \mathrm{ha}$, for a range of timber volume change from $19 \mathrm{~m}^{3} /$ ha to $122 \mathrm{~m}^{3} /$ ha, is poor. The accuracy is higher when analysis is limited to the young stands, but even then the results from this experiment produce lower accuracy results than the previous experiment. The high error in this experiment occurs because the error from the 1991 and 2000 estimates are propagated through to the final estimate of change.

The propagation of errors from the 1991 estimates and 2000 estimates into the final estimate of height or volume change can be estimated with the error propagation equation:

$$
\text { Expected_RMSE } E_{\text {growth_estimate }}=\sqrt{R M S E_{1991 \_e s t i m a t e}^{2}+R M S E_{2000 \_ \text {estimate }}^{2}}
$$

Table 5 shows the observed errors produced by differencing the 1991 and 2000 estimates of height and volume and the expected error, calculated from equation (3), based on the RMSE values for 1991 and 2000. The percentage difference between the observed RMSE and the expected RMSE is also given in table 5. The error propagation equation estimates for the 'mature' and 'young and mature' classes are generally within $6 \%$ of the RMSE found experimentally, with the exception of stand height for the 'mature in 1991' class which is underestimated by $10.9 \%$. For the 'young in 1991' and 'young in 2000' classes the 
error propagation model overestimates by between $11 \%$ and $26 \%$. This indicates a slight systematic bias within the 1991 and 2000 estimates for some stands, which is not accounted for by the error propagation equation, so leads the observed error to be slightly lower than the expected error.

Analysis of the volume change residuals for the 'young in 2000' class reveals a trend between the errors in the 1991 and 2000 estimates $\left(r^{2}=0.50\right)$, with 20 stands being underestimated in both 1991 and 2000, whilst 13 stands were overestimated in both 1991 and 2000. The remaining 15 stands were overestimated for one date and underestimated for the other. For the mature stands there are no trends in the residuals for the two dates. The trend in the young stands may indicate some unaccounted for stand structural factor, which is biasing the results for both sensors in a systematic way. This is possibly due to either the interaction between incidence angle and stand row structure, or the pre-dominance of yield class 14 in the 'young in 2000 ' stands (36 yield class 14 stands compared to 12 other stands).

This method produces lower accuracy than the backscatter difference method, even though substantially more input data were used to generate the stand change estimates. However, comparison of the observed error against the expected error, using the error propagation equation, shows that the estimation accuracy for the younger stands is still higher than expected. 


\subsection{E-SAR minus AirSAR difference image}

Overall, the backscatter ratio change image performs best with $82 \%$ of stands correctly classified (table 6). However, it performs more poorly than the other two methods for the new stands, with only $69 \%$ of stands correctly identified, compared to $74 \%$ and $85 \%$ for the backscatter difference image and the L-HV backscatter image respectively (tables $7 \& 8$ ). The addition of multi-temporal data does improve the accuracy with which stands are identified, when the backscatter ratio change method is used, as it enables greater separation of the young and mature stands, which are poorly separated by the other two methods.

\section{Discussion}

This paper tested three different methods of monitoring forest change over 9 years from airborne SAR data. The results show:

- Multi-temporal L-band SAR data can be used to monitor and quantify growth rates of younger stands, by relating backscatter change to stand height change.

- Signal saturation prevents the use of multi-temporal L-band SAR backscatter for accurately monitoring growth of mature forest stands, when the stands are beyond saturation point for both image acquisitions.

- From a methodological perspective the work suggests that estimating growth indirectly from estimates of height/volume in 1991 and 2000 is highly susceptible to error propagation, whilst the estimation of growth from backscatter difference is more robust and hence preferable. 
- Dual-date L-band SAR data, from different airborne sensors, can increase the accuracy of stand-age classification compared to single-date imagery, as it improves the separation of young and mature stands.

This suggests L-band SAR backscatter could potentially be used to monitor initial growth rates of stands to ensure growth proceeds according to expected forest growth forecasts and to map broad age classes. However, this does require some ground data to generate the empirical relationship and this may limit the utility of the methods described in some cases.

Thetford forest is highly managed and the topography is relatively flat, as such it represents an 'ideal' test site. Factors which could complicate analysis such as mountainous topography, high within stand age diversity, species heterogeneity and lack of coherent geographical units for analysis are limited. One consequence of the FC management is that a high level of correlation exists between biophysical variables, such as stand height, volume, biomass, age, basal area and density. Hence, a correlation between backscatter and one variable implies some degree of correlation between backscatter and the other biophysical variables. The high accuracy of the stand growth estimates from the E-SAR and AirSAR backscatter difference (table 4), is partly due to the strong relationships between stand height and stand height change, as stand height in 1991 and stand height change between 1991 and 2000 are highly correlated, r=0.93. Further investigation showed that a linear relationship developed between AirSAR P-HV $\sigma^{0}$ and height change, between $1991-2000$, was able to reproduce a similar level of accuracy $\left(\mathrm{RMSE}=0.66 \mathrm{~m} ; \mathrm{r}^{2}=0.59\right)$ to that achieved via the E-SAR and AirSAR backscatter difference (section 3.1; table 4) and higher than the height differencing (section 3.2; table 5). This illustrates both the high level 
of consistency between current and future state, within the managed forest stands, and a level of data redundancy in the SAR data sets.

Calibration is a critical issue in the analysis of multi-temporal remote sensing data sets, particularly when data from different sensors are being compared. The availability of the FC data base and yield models enabled us to create empirical relationships between the AirSAR data and the forest state in 1991 and between the ESAR data and the forest state in 2000. It also enabled us to determine the degree of change between the two dates and hence to train the neural networks to estimate this change based on the difference in backscatter. Consequently, the neural networks implicitly calibrated for differences in input data and any differences in scene moisture levels and their resultant impact on backscatter. Extensive calibration would be required to use the same relationship, for example, between L-HV backscatter and mean stand height to estimate stand height from both the 1991 and 2000 data.

Due to the ground data available for Thetford it was possible for us to avoid postproduction calibration. The launch of repeat-pass interferometric SAR (InSAR) sensors, particularly L-band sensors, such as ALOS-PALSAR, SEACOM-1 and the proposed TerraSAR-L, will increase the capabilities of spaceborne SAR for forestry applications, including monitoring temporal change. Spaceborne sensors will increase the availability of time-series of data from a single sensor, so removing the need for inter-sensor calibration, although environmental conditions and sensor degradation will still need to be accounted for.

The key limitation of work, such as this, based on empirical relationships is the need for extensive ground data or proxy ground data to initially parameterise the empirical 
relationship. Future work will explore more physically based modeling methods to exploit the full polarimetric InSAR (PolInSAR) potential of the E-SAR data set.

\section{Acknowledgements}

This research was funded under the BNSC-LINK Carbon project no. R4/039 with support from Biffaward, EcoSecurities Ltd. and SGS Ltd. The AirSAR data are courtesy of NASAJPL. The E-SAR data were acquired during the SHAC 2000 campaign by NERC/BNSC. We would like to extend our thanks to the Forestry Commission for making available the GIS database, and to all those involved in the Thetford fieldwork campaigns in 2000 and 1989.

\section{References}

BAKER, J.R. and MITCHELL, P.L., 1992, The UK element of the maestro-1 SAR campaign. International Journal of Remote Sensing, 13, 1593-1608.

BAKER, J.R., MITCHELL, P.L., CORDEY, R.A., GROOM, G.B., SETTLE, J.J. and STILEMAN, M.R., 1994, Relationships between physical characteristics and polarimetric radar backscatter. International Journal of Remote Sensing, 15, 2827-2849.

BALZTER, H., SKINNER, L., LUCKMAN, A. and BROOKE, R., 2003, Estimation of tree growth in a conifer plantation over nineteen years from multi-satellite L-band SAR. Remote Sensing of Environment, 84,184-191. 
CONWAY, J., 1997, Evaluating ERS-1 SAR data for the discrimination of tropical forest from other tropical vegetation types in Papua New Guinea. International Journal of Remote Sensing, 18, 2967-2984.

DLR (2007), E-SAR data sheet, Available online at: http://www.dlr.de/hr/institut/abteilungen/sar technologie/flugzeug sar/airborne sar/E SA R_data_sheet.pdf (accessed $2^{\text {nd }}$ March 2007).

DOBSON, M.C., ULABY, F.T., LE TOAN, T., BEAUDOIN, A., KASISCHKE, E.S. and CHRISTENSEN, N., 1992, Dependence of radar backscatter on coniferous forest biomass. IEEE Transactions On Geoscience and Remote Sensing, 30, 412-415.

DOBSON, M.C., UlABY, F.T., PIERCE, L.E., SHARIK, T.L., BERGEN, K.M., KELLNDORFER, J., KENDRA, J.R., LI, E., LIN, Y.C., NASHASHIBI, A., SARABANDI, K. and SIQUEIRA, P., 1995, Estimation of forest biophysical characteristics in Northern Michigan with SIR-C/X-SAR. IEEE Transactions On Geoscience and Remote Sensing, 33, 877-894.

EDWARDS, P.N. and CHRISTIE, J.M., 1981, Yield models for forest management, Forestry Commission booklet 48. Farnham: Forestry Commission.

FERRAZZOLI, P., PALOSCIA, S., PAMPALONI, P., SCHIAVON, G., SIGISMONDI, S., and SOLIMINI, D., 1997, The potential of multifrequency polarimetric SAR in assessing agricultural and arboreous biomass. IEEE Transactions On Geoscience and Remote Sensing, 35, 5-17.

FRANSSON, J.E.S. and ISRAELSSON, H., 1999, Estimation of stem volume in boreal forests using ERS-1 C- and JERS L-band SAR data. International Journal of Remote Sensing, 20,123-137. 
FRANSSON, J.E.S., SMITH, G., ASKNE, J. and OLSSON, H., 2001, Stem volume estimation in boreal forests using ERS-1/2 coherence and SPOT XS optical data. International Journal of Remote Sensing, 22, 2777-2791.

FRANSSON, J.E.S., WALTER, F. and ULANDER, L.M.H., 2000, Estimation of forest parameters using CARABAS-II VHF SAR data. IEEE Transactions On Geoscience and Remote Sensing, 38, 720-727.

GUPTA, J., OLSTHOORN, X. and ROTENBERG, E., 2003, The role of scientific uncertainty in compliance with the Kyoto Protocol to the Climate Change Convention. Environmental Science and Policy, 6, 475-486.

HAMILTON, G.J., 1975, Forest Mensuration, Forestry Commission Booklet 39. Farnham: Forestry Commission.

HARRELL, P.A., BOURGEAU-CHAVEZ, L.L., KASISCHKE, E.S., FRENCH, N.H.F. and CHRISTENSEN, N.L., 1995, Sensitivity of ERS-1 and JERS-1 radar data to biomass and stand structure in Alaskan boreal forest. Remote Sensing of Environment, 54, 247-253. HARRELL, P.A., KASISCHKE, E.S., BOURGEAU-CHAVEZ, L.L., HANEY, E.M. and CHRISTENSEN, N.L., 1997, Evaluation of approaches to estimating aboveground biomass in Southern pine forests using SIR-C data. Remote Sensing of Environment, 59, 223-233.

R. HORN, 1996, The DLR Airborne SAR Project E-SAR. In Proc. IEEE International Geoscience and Remote Sensing Symposium (IGARSS) 1996 Lincoln, Nebraska, (Piscataway: IEEE), vol. 3, pp. 1624-1628. 
IMHOFF, M.L., 1995a, A theoretical-analysis of the effect of forest structure on syntheticaperture radar backscatter and the remote-sensing of biomass. IEEE Transactions On Geoscience and Remote Sensing, 33, 341-352.

IMHOFF, M.L., 1995b, Radar backscatter and biomass saturation - Ramifications for global biomass inventory. IEEE Transactions On Geoscience and Remote Sensing, 33, 511518.

KASISCHKE E.S., CHRISTENSEN, N.L. and BOURGEAU-CHAVEZ, L.L., 1995, Correlating radar backscatter with components of biomass in loblolly pine forest. IEEE Transactions On Geoscience and Remote Sensing, 33, 643-659.

KASISCHKE, E.S., MELACK, J.M. and DOBSON, C., 1997, The use of imaging radars for ecological applications - A review. Remote Sensing of Environment, 59, 141-156.

KURVONEN, L., PULLIANINEN, J. and HALLIKAINEN, M., 1999, Retrieval of biomass in Boreal forests from multitemporal ERS-1 and JERS-1 SAR images. IEEE Transactions On Geoscience and Remote Sensing, 37,198-205.

LE TOAN, T., BEAUDOIN, A., RIOM, J. and GUYON, D., 1992, Relating forest biomass to SAR data. IEEE Transactions On Geoscience and Remote Sensing, 30, 403-411.

LEVY, P.E., HALE, S.E. and NICOLL, B.C., 2004, Biomass expansion factors and root : shoot ratios for coniferous tree species in Great Britain. Forestry, 77, 421-430.

LOU, Y., KIM, Y. and VAN ZYL, J., 1996, The NASA/JPL airborne synthetic aperture radar system, In Summaries of the Sixth Annual Airborne Science Workshop, Y. Kim (Ed.), (California: Jet Propulsion Laboratory (JPL)), vol. 2, pp. 51-56. 
LUCAS, R. M., CRONIN, N., LEE, A., MOGHADDAM, M., WITTE, C. and TICKLE, P., 2006, Empirical relationships between AIRSAR backscatter and LiDAR-derived forest biomass, Queensland, Australia. Remote Sensing of Environment, 100, 407-425.

LUCKMAN, A. and BAKER, J., 1994, Technical note on selection of forest data: Thetford forest SAR database. Remote Sensing Applications Development Unit (RSADU) report no. 94/7, CEH Monks Wood, Huntingdon, UK.

MILES, V.V., BOBYLEV, L.P., MAXIMOV, S.V., JOHANNESSEN, O. and PITULKO, V.M., 2003, An approach for assessing boreal forest conditions based on combined use of satellite SAR and multi-spectral data. International Journal of Remote Sensing, 20, 44474466.

PULLIANIEN, J., ENGDAHL, M. and HALLIKAINEN, M., 2003, Feasibility of multitemporal interferometric SAR data for stand-level estimation of boreal forest stem volume. Remote Sensing of Environment, 85, 397-409.

QUEGAN, S., LE TOAN, T., YU, J.J., RIBBES, F. and FLOURY, N., 2000, Multitemporal ERS SAR analysis applied to forest mapping. IEEE Transactions On Geoscience and Remote Sensing, 38, 741-753.

RANSON, K.J., KOVACS, K., SUN, G. and KHARUK, V.I., 2003, Disturbance recognition in the boreal forest using radar and Landsat-7. Canadian Journal of Remote Sensing, 29, 271-285.

RANSON, K.J., SAATCHI, S. and SUN, G., 1995, Boreal forest ecosystem characterization with SIR-C/XSAR. IEEE Transactions On Geoscience and Remote Sensing, 33, 867-876. 
RANSON, K.J. and SUN, G., 1994, Mapping biomass of a northern forest using multifrequency SAR data. IEEE Transactions On Geoscience and Remote Sensing, 32, 388-396.

ROWLAND, C.S., BALZTER, H., DAWSON, T.P., LUCKMAN, A., SKINNER, L. and PATENAUDE, G. (2003). Biomass estimation of Thetford forest from L-band SAR data: potential and limitations. Proc. IEEE International Geoscience and Remote Sensing Symposium (IGARSS) 2003, 21-25 July, Toulouse, CD-ROM.

SAICH, P., LEWIS, P., DISNEY, M., VAN OEVELEN, P., WOODHOUSE, I., ANDRIEU, B., FOURNIER, C. and LJUTOVAC S., 2003, Development of Architectural Vegetation Growth Models for Remote Sensing Applications, ESA Report contract 14940, Available online at: http://www.geog.ucl.ac.uk/ psaich/esa/ (accessed $2^{\text {nd }}$ March 2007).

SKINNER, L., 2002, Estimating forest parameters from Synthetic Aperture Radar: A case study of Thetford forest. Unpublished PhD thesis, Swansea: University of Wales.

SMITH, G. and ASKNE, J., 2001, Clear-cut detection using ERS interferometry. International Journal of Remote Sensing, 22, 3651-3664.

VAN DE GRIEND, A. and SEYHAN, E., 1999, Multi-temporal analysis of ERS-1 and EMISAR C-band VV backscattering properties of forest and lake surfaces in the NOPEX region. Agricultural and Forest Meteorology, 98-99, 363-374.

VAN ZYL, J.J., 1992, AirSAR general reference manual, Available online at: (http://airsar/jpl.nasa.gov/documents/instrument.html (accessed $2^{\text {nd }}$ March 2007). 
WANG, Y., KASISCHKE, E.S., MELACK, J.M., DAVIS, F.W. and CHRISTENSEN, N.L., 1994, The effects of changes in Lobolly pine biomass and soil moisture on ERS-1 SAR backscatter. Remote Sensing of Environment, 49, 25-31. 


\section{Figure Headings}

Figure 1. Histograms showing degree of forest age class separability for (a) ratio between AirSAR and E-SAR (from equation (1)); (b) difference between AirSAR and E-SAR where AirSAR > E-SAR (from equation (2)); (c) difference between AirSAR and E-SAR where AirSAR $<$ E-SAR (from equation (2)); and (d) E-SAR L-HV backscatter.

Figure 2. Estimated change between 1991 and 2000 from mean stand L-band backscatter difference compared to expected change based on the FC GIS data, for (a) stand height and (b) stand volume.

Figure 3. Estimated tree height for (a) 1991 AirSAR data and (b) 2000 E-SAR data; and (c) estimated stand height change from stand height estimates in (a) and (b). Stands clear-cut between 1991 and 2000 were excluded from this analysis, which is why there are no stands below approx. $3.5 \mathrm{~m}$ in (b). 
Figure 1
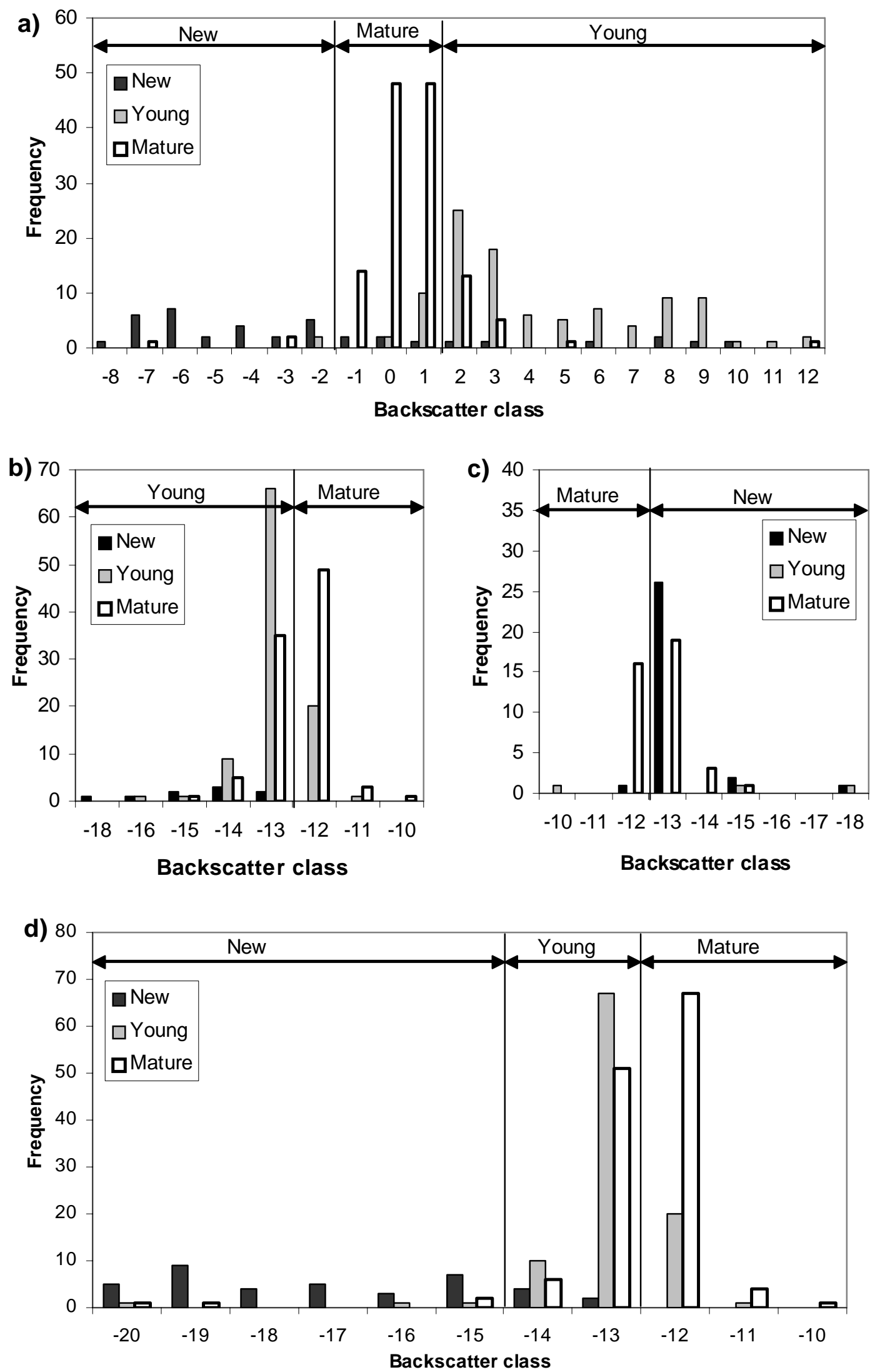
Figure 2

a)

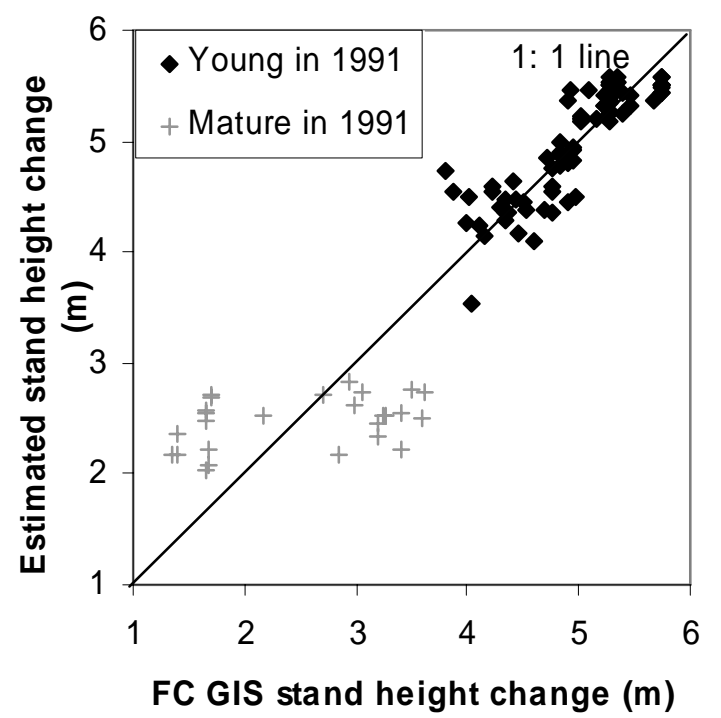

b)

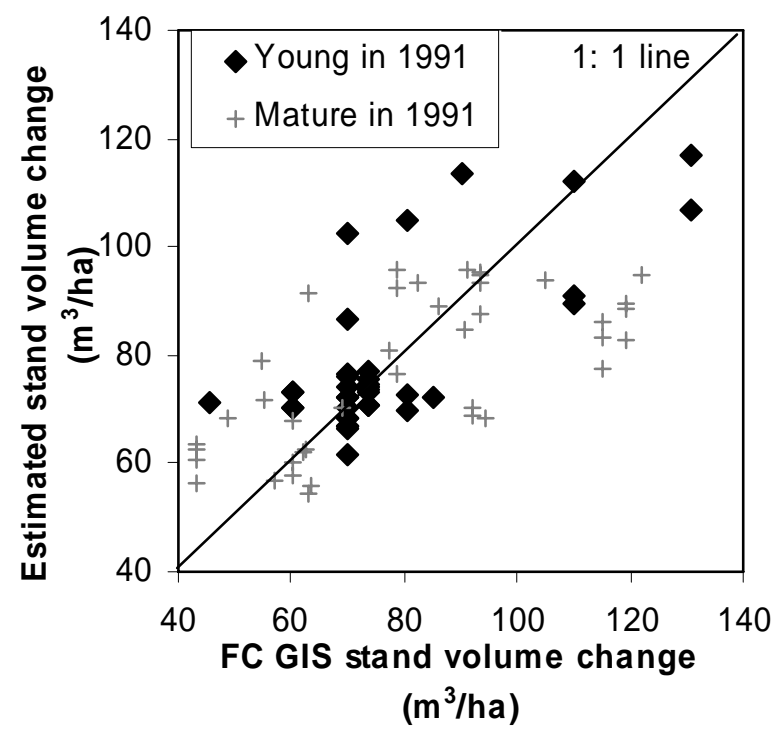


Figure 3

a)

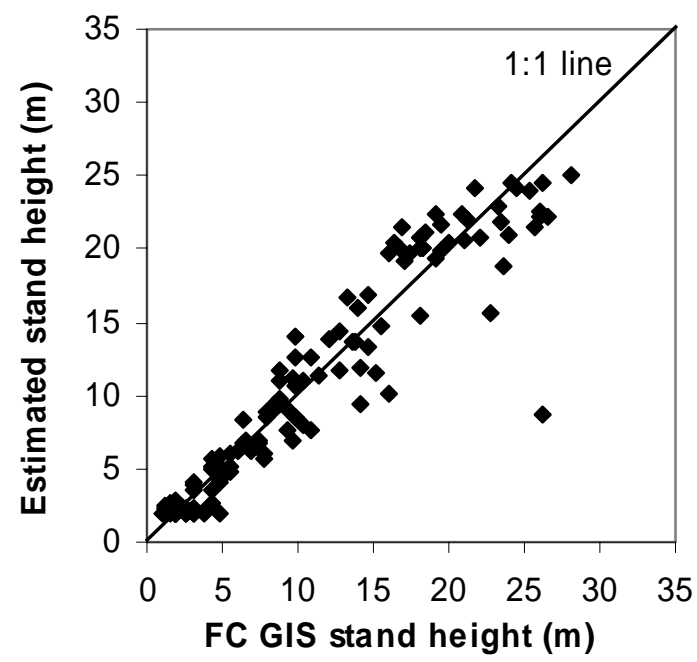

c)

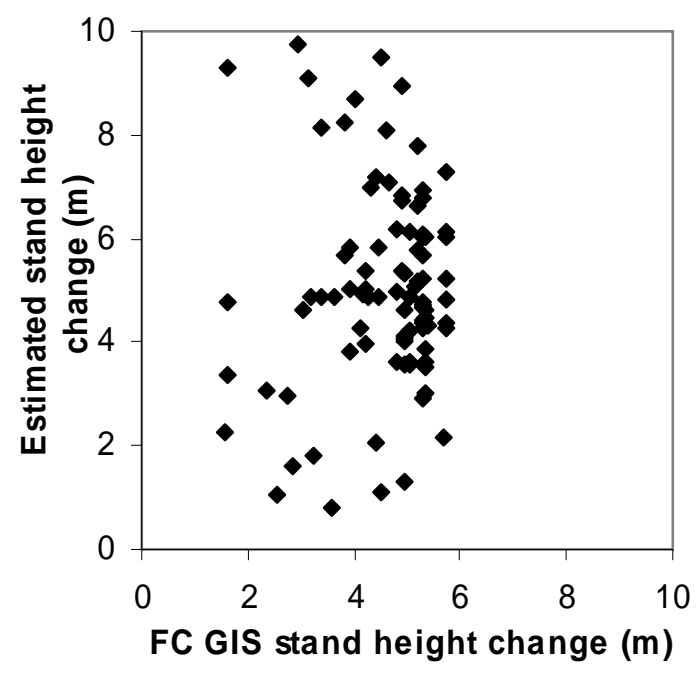

c) b)

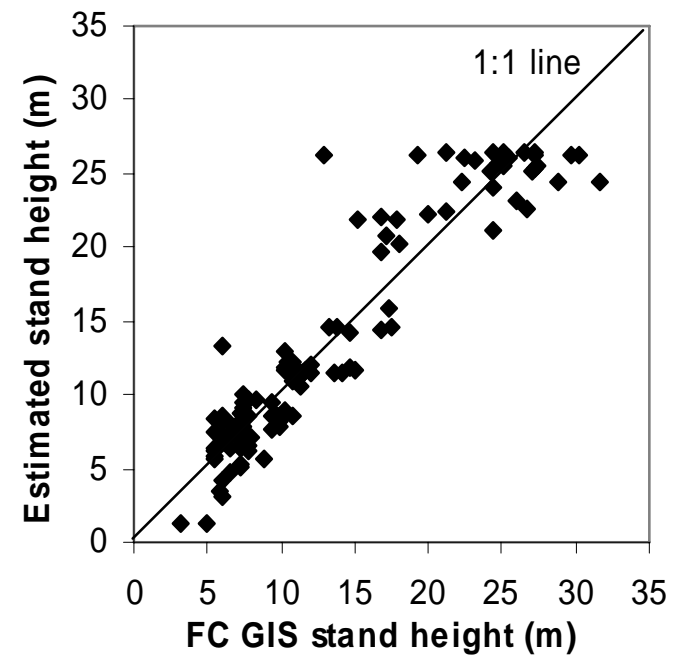


Table 1. Comparison of field derived measurements of stand height and volume, compared to FC yield model extrapolated (stands above 15-20 years) and interpolated (stands below 15-20 years) estimates. The age range for the cut-off point between extrapolated and interpolated stands is due to the different yield classes.

\begin{tabular}{|c|c|c|c|c|}
\hline \multirow{2}{*}{$\begin{array}{l}\text { Field measured } \\
\text { stands }\end{array}$} & \multicolumn{2}{|c|}{ Height (m) } & \multicolumn{2}{|c|}{ Volume $\left(\mathrm{m}^{3} / \mathrm{ha}\right)$} \\
\hline & RMSE & Range & RMSE & Range \\
\hline $\begin{array}{l}\text { Extrapolated stands } \\
\text { (14 stands) }\end{array}$ & 0.99 & $1.8-9.5$ & 26.28 & $6-144$ \\
\hline $\begin{array}{l}\text { Interpolated stands } \\
\text { (10 stands) }\end{array}$ & 1.06 & $10-30.0$ & 45.25 & $153-606$ \\
\hline $\begin{array}{l}\text { All field measured } \\
\text { stands ( } 24 \text { stands) }\end{array}$ & 1.02 & $1.8-30.0$ & 34.63 & $6-606$ \\
\hline
\end{tabular}


Table 2. Airborne sensor characteristics for Thetford radar data.

\begin{tabular}{|c|c|c|c|c|c|c|}
\hline \multirow[t]{2}{*}{ Sensor } & \multirow[t]{2}{*}{ Channels } & \multirow{2}{*}{$\begin{array}{l}\text { Incidence } \\
\text { angle }\left({ }^{\circ}\right)\end{array}$} & \multirow{2}{*}{$\begin{array}{l}\text { Images } \\
\text { acquired }\end{array}$} & \multicolumn{2}{|c|}{ Pixel spacing (m) } & \multirow{2}{*}{$\begin{array}{l}\text { Imaged } \\
\text { area }^{a}\end{array}$} \\
\hline & & & & Azimuth & Range & \\
\hline AirSAR & $\begin{array}{l}\text { C-HH, -HV, -VV } \\
\text { L-HH, -HV, -VV } \\
\text { P-HH, -HV, -VV }\end{array}$ & $24-57$ & $28 / 07 / 91$ & 12.1 & 6.6 & $\begin{array}{l}12 \mathrm{~km} \\
12 \mathrm{~km}\end{array}$ \\
\hline $\begin{array}{l}\text { E-SAR } \\
\text { (wide } \\
\text { swath } \\
\text { mode) }\end{array}$ & $\begin{array}{l}\text { L-HH, -HV, -VV } \\
\text { Interferometric } \\
\text { coherence at } \\
\text { L-HH, -HV, -VV } \\
\text { X-VV }\end{array}$ & $30-68$ & $31 / 05 / 00$ & 3.7 & 1.0 & $\begin{array}{l}8 \mathrm{~km} \\
5 \mathrm{~km}\end{array}$ \\
\hline
\end{tabular}

a - Only the area common to both images was used for the analysis in this paper. 
Table 3. The three classes of stand-age, with associated tree height and tree volume ranges.

\begin{tabular}{llllll}
\hline Class & $\begin{array}{l}\text { Age in } \\
2000\end{array}$ & $\begin{array}{l}\text { Feature in } \\
\text { experiment }\end{array}$ & $\begin{array}{l}\text { Number } \\
\text { of stands }\end{array}$ & $\begin{array}{l}\text { Tree height } \\
\text { range }(\mathrm{m})\end{array}$ & $\begin{array}{l}\text { Tree volume } \\
\text { range }\left(\mathrm{m}^{3} / \mathrm{ha}\right)\end{array}$ \\
\hline $\begin{array}{l}\text { New } \\
\text { stands }\end{array}$ & $0-9$ years & 3 & 39 & Up to $3.5 \mathrm{~m}$ & Up to 45 \\
$\begin{array}{l}\text { Young } \\
\text { stands }\end{array}$ & $\begin{array}{l}10-20 \\
\text { years }\end{array}$ & $1,2,3$ & 101 & $3.5 \mathrm{~m}-11 \mathrm{~m}$ & $32-163$ \\
$\begin{array}{l}\text { Mature } \\
\text { stands }\end{array}$ & $\begin{array}{l}\text { 20 years } \\
+\end{array}$ & $1,2,3$ & 133 & $9 \mathrm{~m}-32 \mathrm{~m}$ & $120-650$ \\
\hline
\end{tabular}


Table 4. Estimates of growth between 1991 and 2000 from mean L-band stand backscatter difference. Note young and mature are the age classes defined in Table 3 and are based on age in 1991 or 2000 as stated.

\begin{tabular}{lll}
\hline Age class & $\begin{array}{l}\text { Height change } \\
\text { RMSE }(\mathrm{m})\end{array}$ & $\begin{array}{l}\text { Timber volume } \\
\text { change RMSE } \\
\left(\mathrm{m}^{3} / \mathrm{ha}\right)\end{array}$ \\
\hline $\begin{array}{l}\text { Young and } \\
\text { mature }\end{array}$ & 0.42 & 15.73 \\
$\begin{array}{l}\text { Young in } \\
\begin{array}{l}\text { Y000 } \\
\text { Mature in }\end{array}\end{array}$ & 0.20 & 12.56 \\
$\begin{array}{l}\text { 2000 } \\
\text { Young in }\end{array}$ & 0.52 & 18.18 \\
$\begin{array}{l}\text { 1991 } \\
\text { Mature in } \\
1991\end{array}$ & 0.64 & 15.00 \\
\hline
\end{tabular}


Table 5. RMSE values for estimates of stand height and volume from AirSAR data in 1991 and E-SAR data in 2000. Stand height or volume change were estimated from the difference between the 1991 and 2000 estimates. Young and mature are the age classes defined in Table 3 and are based on age in 1991 or 2000 as stated.

\begin{tabular}{|c|c|c|c|c|c|c|}
\hline & Age class & $\begin{array}{l}\text { AirSAR } \\
\text { RMSE }\end{array}$ & $\begin{array}{l}\text { E-SAR } \\
\text { RMSE }\end{array}$ & $\begin{array}{l}\text { Observed } \\
1991- \\
2000 \\
\text { growth } \\
\text { RMSE }\end{array}$ & $\begin{array}{l}\text { Error } \\
\text { propagation } \\
\text { expected } \\
1991-2000 \\
\text { growth } \\
\text { RMSE }\end{array}$ & $\begin{array}{l}\text { Percentage } \\
\text { difference } \\
\text { between } \\
\text { observed } \\
\text { and } \\
\text { expected } \\
\text { RMSE }\end{array}$ \\
\hline \multirow{5}{*}{$\begin{array}{l}\text { Timber } \\
\text { volume } \\
\left(\mathrm{m}^{3} / \mathrm{ha}\right)\end{array}$} & Young and mature & 35.99 & 65.14 & 70.29 & 74.42 & 5.9 \\
\hline & Young in 2000 & 9.95 & 33.90 & 27.94 & 35.33 & 26.4 \\
\hline & Mature in 2000 & 46.49 & 80.52 & 89.18 & 92.98 & 4.3 \\
\hline & Young in 1991 & 14.86 & 51.88 & 48.61 & 53.97 & 11.0 \\
\hline & Mature in 1991 & 61.67 & 88.67 & 104.67 & 108.01 & 3.2 \\
\hline \multirow{5}{*}{$\begin{array}{l}\text { Stand } \\
\text { height } \\
\text { (m) }\end{array}$} & Young and mature & 1.75 & 2.50 & 2.93 & 3.05 & 4.2 \\
\hline & Young in 2000 & 1.13 & 1.09 & 1.38 & 1.57 & 13.8 \\
\hline & Mature in 2000 & 2.09 & 3.16 & 3.67 & 3.79 & 3.2 \\
\hline & Young in 1991 & 1.23 & 2.05 & 2.16 & 2.39 & 10.7 \\
\hline & Mature in 1991 & 1.75 & 3.33 & 4.22 & 3.76 & -10.9 \\
\hline
\end{tabular}


Table 6. Assessment of ratio change image performance, at stand level, for stand age-class identification. The split between age classes is based on age in 2000 (see Table 3). Overall accuracy $=82 \%$.

\begin{tabular}{|c|c|c|c|c|c|c|}
\hline & & \multicolumn{5}{|c|}{ FC classes } \\
\hline \multirow{6}{*}{$\begin{array}{l}\text { SAR } \\
\text { classes }\end{array}$} & & $\begin{array}{l}\text { New } \\
\text { stands }\end{array}$ & $\begin{array}{l}\text { Young } \\
\text { stands }\end{array}$ & $\begin{array}{l}\text { Mature } \\
\text { stands }\end{array}$ & $\begin{array}{l}\text { Row } \\
\text { Total }\end{array}$ & $\begin{array}{r}\text { User's } \\
\text { accuracy } \\
(\%)\end{array}$ \\
\hline & New stands & 27 & 2 & 3 & 32 & 84 \\
\hline & Young stands & 7 & 87 & 20 & 114 & 76 \\
\hline & Mature stands & 5 & 12 & 110 & 127 & 87 \\
\hline & Column total & 39 & 101 & 133 & 273 & \\
\hline & $\begin{array}{l}\text { Producer's } \\
\text { accuracy }(\%)\end{array}$ & 69 & 86 & 83 & & \\
\hline
\end{tabular}


Table 7. Assessment of difference change image performance, at stand level, for stand ageclass identification. The split between age classes is based on age in 2000 (see Table 3). Overall accuracy $=64 \%$.

\begin{tabular}{|c|c|c|c|c|c|c|}
\hline \multirow{7}{*}{$\begin{array}{l}\text { SAR } \\
\text { classes }\end{array}$} & & \multicolumn{5}{|c|}{ FC classes } \\
\hline & & $\begin{array}{l}\text { New } \\
\text { stands }\end{array}$ & $\begin{array}{l}\text { Young } \\
\text { stands }\end{array}$ & $\begin{array}{l}\text { Mature } \\
\text { stands }\end{array}$ & $\begin{array}{l}\text { Row } \\
\text { Total } \\
\end{array}$ & $\begin{array}{r}\text { User's } \\
\text { accuracy } \\
(\%) \\
\end{array}$ \\
\hline & New stands & 29 & 2 & 23 & 54 & 54 \\
\hline & Young stands & 9 & 77 & 41 & 127 & 61 \\
\hline & Mature stands & 1 & 22 & 69 & 92 & 75 \\
\hline & Column total & 39 & 101 & 133 & 273 & \\
\hline & $\begin{array}{l}\text { Producer's } \\
\text { accuracy (\%) }\end{array}$ & 74 & 76 & 52 & & \\
\hline
\end{tabular}


Table 8. Assessment of L-HV backscatter image performance, at stand level, for stand ageclass identification. The split between age classes is based on age in 2000 (see Table 3). Overall accuracy $=67 \%$.

\begin{tabular}{|c|c|c|c|c|c|c|}
\hline & & \multicolumn{5}{|c|}{ FC classes } \\
\hline \multirow{6}{*}{$\begin{array}{l}\text { SAR } \\
\text { classes }\end{array}$} & & $\begin{array}{l}\text { New } \\
\text { stands }\end{array}$ & $\begin{array}{l}\text { Young } \\
\text { stands }\end{array}$ & $\begin{array}{l}\text { Mature } \\
\text { stands }\end{array}$ & $\begin{array}{l}\text { Row } \\
\text { Total }\end{array}$ & $\begin{array}{r}\text { User's } \\
\text { accuracy } \\
(\%)\end{array}$ \\
\hline & New stands & 33 & 3 & 4 & 40 & 83 \\
\hline & Young stands & 6 & 77 & 57 & 140 & 55 \\
\hline & Mature stands & 0 & 21 & 72 & 93 & 77 \\
\hline & Column total & 39 & 101 & 133 & 273 & \\
\hline & $\begin{array}{l}\text { Producer's } \\
\text { accuracy }(\%)\end{array}$ & 85 & 76 & 54 & & \\
\hline
\end{tabular}

